\title{
Pengaruh Latihan Kapha Yoga terhadap Penurunan Tekanan Darah dan Peningkatan Kebugaran Lansia
}

\section{Influence of Exercise Kapha Yoga Against a Decrease in Blood Pressure and an Increase in the Elderly Fitness}

\author{
Moch. Arif Romadlon, Eka Nugraha \& Hamidie Ronald D \\ Universitas Pendidikan Indonesia, Bandung, Jawa Barat, Indonesia \\ arifugym@gmail.com
}

Naskah diterima tanggal 19/02/2019, direvisi akhir tanggal 22/04/2019, disetujui tanggal 30/04/2019

\begin{abstract}
Abstrak
Tujuan penelitian ini untuk mengetahui pengaruh latihan kapha yoga terhadap penurunan tekanan darah dan peningkatan kebugaran lansia. Metode penelitian ini adalah eksperimen dengan desain penelitian kausal komparatif atau ex-postfacto yang membandingkan dua kelompok eksperimen dan kelompok kontrol. Teknik pengambilan sampling yaitu sampling purposive. Populasi dalam penelitian ini adalah semua lansia yang sudah didiagnosa oleh dokter positif menderita hipertensi adalah kelompok eksperimen 15 orang lansia dengan rentan usia 60-74 tahun di Apotek Izzatul Komplek Puri Cipageran Indah 1 Blok B 42 Cimahi dan kelompok kontrol 15 orang lansia dengan rentang usia 60-74 tahun di Lapangan Primarobic Jatihandap gg.3 Rt: 04 / Rw: 04 Cicaheum, Kota Bandung. Instrument penelitian ini adalah mengadopsi dari journal C. Jessie Jones dan Roberta E. Rikli pada tahun 2002 yang menggunakan The Seniors Fitness Test. Hasil penelitian menunjukan adanya penurunan tekanan darah dan peningkatan kebugaran lansia yang signifikan oleh kelompok eksperimen selama 24 kali pertemuan.
\end{abstract}

Kata Kunci: hipertensi, kapha yoga, kebugaran, lansia.

\begin{abstract}
The purpose of this research is to know the influence of exercise Kapha yoga against a decrease in blood pressure and an increase in fitness of the elderly. The method of this research is an experiment with causal-comparative design research or ex-post facto comparing two experimental groups and control group. Retrieval technique of sampling that is purposive sampling. The population in this research is all the elderly who have been diagnosed by a doctor suffering from hypertension is a positive Group of experimental vulnerable elderly with 15 people aged 60-74 years in Pharmacy Izzatul Beautiful Cipageran Castle 1 Complex Blocks B 42 Cimahi and a control group of 15 elderly people with an age range 60-74 years in the field Primarobic Jatihandap gg 3 Rt: 04/Rw: 04 Cicaheum, Bandung. The research instrument was adopted from journal c. Jessie Jones and Roberta e. Rikli in 2002 that uses The Seniors Fitness Test showed the presence of research results. the decrease in blood pressure and a significant increase in the elderly fitness experiments by the group for 24 times.
\end{abstract}

Keywords: elderly, fitness, hypertension, kapha yoga.

\section{PENDAHULUAN}

Di era globalisasi ini, kecenderungan aktivitas rutin yang padat menjadikan manusia sedikit atau bahkan hampir tidak pernah menyisihkan waktu untuk berolahraga, sehingga ancaman berbagai macam penyakit kian menyerang seperti obesitas, hipertensi dan sebagainya. Kebutuhan aktivitas fisik yang sesuai sangat 
diperlukan guna peningkatan kesehatan manusia. Diantara sekian banyak jenis aktivitas fisik, Yoga merupakan salah satu alternatif yang dapat dilakukan di sela rutinitas kerja baik di pagi hari maupun sore hari. Manfaat Yoga tidak hanya membantu tubuh menjadi lebih segar dan bugar, juga dapat membantu dalam mengendalikan stres dan mengurangi rasa mudah gelisah. Olahraga ini juga memberikan manfaat bagi balancing mind, body, and soul (Anggraeni, 2017). Dan diperkuat bahwa Yoga adalah pola latihan untuk memperoleh manfaat kesehatan fisik dan mental dengan mengatur sumbu hipotalamus, hipofisis, adrenal dan simpa sintetik yang memicu terjadinya respon sistem saraf stres (Ross \& Thomas, 2010).

Hipertensi atau tekanan darah tinggi merupakan salah satu penyakit yang mempunyai hubungan yang sangat erat dengan lansia (Rahajeng \& Tuminah, 2009). Hal ini terjadi akibat perubahan fisiologis yang terjadi seperti penurunan respons imunitas tubuh, katup jantung menebal dan menjadi kaku, penurunan kemampuan kontraktilitas jantung, berkurangnya elastisitas pembuluh darah, serta kurangnya efektifitas pembuluh darah perifer untuk oksigenasi.

PencegahandanPenangananhipertensi dapat dilakukan dengan memperbaiki pola hidup dan dengan terapi farmakologis. Salah satu cara memperbaiki pola hidup adalah dengan melakukan aktivitas fisik yang teratur dan terukur akan mampu mempertahankan kebugaran jasmani dan tingkat konsentrasi lebih lama dibandingkan dengan yang tidak melakukan olahraga secara teratur (Taringan, 2016). Aktivitas fisik terhadap penderita hipertensi bertujuan untuk menurunkan tekanan darah melalui beberapa mekanisme seperti perubahan neurohumoral, adaptasi struktur pembuluh darah, serta penurunan katekolamin dan tahanan perifer total
(Pescatello et al., 2004; U.S. Department of Health and Human Services, 2004).

Kebutuhan aktivitas fisik yang sesuai sangat diperlukan guna peningkatan kesehatan manusia. Olahraga merupakan bagian dari aktifitas fisik, seperti contoh yoga. Yoga adalah olahraga kesehatan yang bermanfaat secara menyeluruh (holistik), efek yoga terhadap kesehatan telah dibuktikan melalui banyak penelitian, diantaranya yaitu Eda et al. (2018:227-244) mengemukakan bahwa peregangan dalam latihan yoga dapat mengurangi tekanan psikologis dan meningkatkan imun mukosa pada wanita usia pertengahan dan lanjut usia. Sedangkan Menurut Sindhu (2009:15) Yoga adalah panduan hidup menuju kesehatan, kedamaian pikiran, dan kebahagiaan. Bisa dilakukan kapan saja dan dimana saja. Sayangnya, hal ini belum banyak disadari. Tak sedikit pula yang menganggap yoga adalah sebuah gaya hidup yang eksklusif dan hanya dilakukan oleh orang-orang tertentu. Maka dari itu yoga cocok untuk siapa saja terutama terhadap lansia, karena dengan melakukan aktivitas yoga yang secara mata mampu menggabungkan unsur psikologis-fisiologis, sementara aktivitas lainnya mayoritas lebih memiliki efek pada unsur fisik luar semata (Lebang, 2010:1).

Lansia dalam menjaga kesehatan tubuhnya perlu melakukan olahraga, dengan olahraga yang bersifat kesehatan dan menjaga kebugaran tubuhnya. Dalam berolahraga ada tujuannya dan tujuan olahraga pada lansia antara lain menurut (Kusmaedi, 2008:116), yakni membantu tubuh agar tetap dapat berberak, lambat laun menaikan kemampuan fisik, memberi kontak psikologis lebih luas agar tidak terisolir dari rangsang, mencegah cedera, meningkatkan dan mempertahankan kesehatan dan meningkatkan kemandirian sehingga lansia dapat melakukan aktivitas sehari-hari. Olahraga yang dianjurkan 
untuk kesehatan ialah suatu aktivitas gerak raga dengan intensitas yang setingkat diatas intensitas gerak raga yang biasa dilakukan untuk keperluan pelaksanaan tugas kehidupan sehari-hari (Blair et al., 1989 dalam Giriwijoyo, 2016:42). Jadi dapat dikatakan bahwa latihan melalui olahraga kesehatan ini memiliki intensitas yang cukup, tidak terlalu tinggi intensitasnya seperti latihan pada olahraga prestasi namun tidak terlalu rendah juga intensitasnya dan dalam gerakan-gerakannya pun tidak boleh ada gerakan yang bersifat explosive, maximal dan emosional sehingga didalamnya pun tidak boleh ada unsur kompetisi.

Salah satu jenis olahraga yang bermanfaat dan tidak menimbulkan dampak buruk adalah yoga. Beberapa teknik dari latihan yoga seperti meditasi dan teknik bernapas memiliki manfaat yang baik bagi tubuh terutama untuk menurunkan tekanan darah, maka yoga sangat direkomendasikan pada penderita tekanan darah tinggi khususnya pada lansia (Dinata, 2015). Latihan yoga secara teratur sangat berpengaruh terhadap kesehatan, baik secara fisik maupun mental. Hal ini diperkuat dengan hasil penelitian dari Naik, Patel, DA, \& Verma (2016) yang menyatakan bahwa yoga dapat meningkatkan konsentrasi, bahkan meningkatkan kecerdasan, keterampilan dan koordinasi.

\section{METODE PENELITIAN}

Dalam penelitian ini penulis mengunakan metode kausal komparatif disebut juga sebagai penelitian ex post facto (Fraenkel, Wallen, \& Hyun, 2012). Penggunaan metode kausal komparatif ini karena dalam penelitiannya penulis ingin mengamati suatu masalah secara mendalam dengan cara membandingkan dua situasi kelompok yang berbeda pretest dan post-test. Desain dasar penelitian kausal komparatif meliputi pemilihan 2 atau lebih kelompok yang berbeda berdasarkan variabel tertentu yang menjadi perhatian dan membandingkannya berdasarkan variabel atau beberapa variabel lainnya (Suherman, 2002:18). Dalam penelitian ini penulis membandingkan kelompok yang diberikan latihan kapha yoga dengan kelompok kontrol yang menjalanjan aktifitas olahraga lain terhadap penurunan tekanan darah dan peningkatan kebugaran.

Populasi dalam penelitian ini adalah semua lansia yang sudah didiagnosa oleh dokter positif menderita hipertensi. Teknik pengambilan sampling yang digunakan yaitu sampling purposive, (Sugiyono, 2016:125) mengungkapkan sampling purposive adalah teknik penentuan sampel dengan pertimbangan tertentu. Alasan peneliti menggunakan tehnik sampling purposive adalah sesuai dengan karakteristik sampel yaitu lansia yang menderita hipertensi yang menjadi objek penelitian, maka dari itu sampelnya adalah kelompok eksperimen 15 orang lansia dengan rentan usia 60-74 tahun di Apotek Izzatul Komplek Puri Cipageran Indah 1 Blok B 42 Cimahi dan kelompok kontrol 15 orang lansia dengan rentang usia 60-74 tahun di Lapangan Primarobic Jatihandap gg.3 Rt: 04 / Rw: 04 Cicaheum, Kota Bandung. Penelitian ini dilakukan selama 2 bulan ( 24 kali pertemuan) dengan intensitas pertemuan 3 kali dalam seminggu, meniru berdasarkan penelitian terdahulu dan juga berdasarkan oleh Anderson \& Bliven (2017). Hal ini diperkuat oleh Raghuraj \& Telles (2004) mengemukan bahwa yoga membantu proses pernafasan dan menurunkan detak jantung. Selain itu, menurut Gain, (2011:190), yoga mengkombinasikan antara teknik bernapas, relaksasi dan meditasi serta latihan peregangan. Dan penjelasan tersebut sangat cocok kaitannya dengan latihan senam yoga yang menitikberatkan pada pernapasan agar mendapatkan ketenangan

Jurnal Penelitian Pendidikan 
dan konsentrasi (Andari, 2017).

Instrument yang digunakan untuk mengukur variabel penelitian ini adalah dengan mengadopsi dari penelitian journal oleh
Jones \& Rikli (2002) yang menggunakan tes The Seniors Fitness Test dengan hasil pada tabel 1 dan tabel 2.

Tabel 1. Tes Latihan Kebugaran Lansia untuk Pria

\begin{tabular}{lrrrrrrr}
\hline & $60-64$ & $65-69$ & $70-74$ & $75-79$ & $80-84$ & $85-89$ & $90-94$ \\
\hline $\begin{array}{l}\text { Chair Stand } \\
\text { (tidak ada tegakan.) }\end{array}$ & $14-19$ & $12-18$ & $12-17$ & $11-17$ & $10-15$ & $8-14$ & $7-12$ \\
\hline $\begin{array}{l}\text { Arm Curl } \\
\text { (tidak ada repetisi.) }\end{array}$ & $16-22$ & $15-21$ & $14-21$ & $13-19$ & $13-19$ & $11-17$ & $10-14$ \\
\hline $\begin{array}{l}\text { 6-MinWalk } \\
\text { (tidak ada dari yds.) }\end{array}$ & $610-735$ & $560-700$ & $545-680$ & $470-640$ & $445-605$ & $380-570$ & $305-500$ \\
\hline $\begin{array}{l}\text { 2-Min Step } \\
\text { (tidak ada langkah- } \\
\text { langkah) }\end{array}$ & $87-115$ & $86-116$ & $80-110$ & $73-109$ & $71-103$ & $59-91$ & $52-86$ \\
\hline $\begin{array}{l}\text { Chair Sit \& -Reach } \\
\text { (inci +/-) }\end{array}$ & $-2,5-4,0$ & $-3,0-3,0$ & $-3,5-2,5$ & $-4,0-2,0$ & $-5,5-1,5$ & $-5,5-0,5$ & $-6,5--0,5$ \\
\hline $\begin{array}{l}\text { Back Scratch } \\
\text { (inci + -) }\end{array}$ & $-6,5-0,0$ & $-7,5--1,0$ & $-8,0--1,0$ & $-9,0--2,0$ & $-9,5--2,0$ & $-10,0--3,0$ & $-10,5--4,0$ \\
\hline $\begin{array}{l}\text { 8-Foot Up \& Go } \\
\text { (detik) }\end{array}$ & $5.6-3,8$ & $5,7-4,3$ & $6,0-4,2$ & $7,2-4,6$ & $7,6-5,2$ & $8,9-5,3$ & $10,0-6,2$ \\
\hline
\end{tabular}

Tabel 2. Tes Latihan Kebugaran Lansia untuk Wanita

\begin{tabular}{lrrrrrrr}
\hline & $60-64$ & $65-69$ & $70-74$ & $75-79$ & $80-84$ & $85-89$ & $90-94$ \\
\hline $\begin{array}{l}\text { Chair Stand } \\
\text { (tidak ada tegakan.) }\end{array}$ & $12-17$ & $11-16$ & $10-15$ & $10-15$ & $9-14$ & $8-13$ & $4-11$ \\
\hline $\begin{array}{l}\text { Arm Curl } \\
\text { (tidak ada repetisi.) }\end{array}$ & $13-19$ & $12-18$ & $12-17$ & $11-17$ & $10-16$ & $10-15$ & $8-13$ \\
\hline $\begin{array}{l}\text { 6-Min Walk } \\
\text { (tidak ada dari yds.) }\end{array}$ & $545-660$ & $500-635$ & $480-615$ & $430-585$ & $385-540$ & $340-510$ & $275-440$ \\
\hline $\begin{array}{l}\text { 2-Min Step } \\
\text { (tidak ada langkah- } \\
\text { langkah.) }\end{array}$ & $75-107$ & $73-107$ & $68-101$ & $68-100$ & $60-91$ & $55-85$ & $44-72$ \\
\hline $\begin{array}{l}\text { Chair Sit \& Reach } \\
\text { (inci +/-) }\end{array}$ & $-0,5-5,0$ & $-0,5-4,5$ & $-1,0-4,0$ & $-1,5-3,5$ & $-2,0-3,0$ & $-2,5-2,5$ & $-4,5-1,0$ \\
\hline $\begin{array}{l}\text { Back Scratch } \\
\text { (inci + -) }\end{array}$ & $-3,0-1,5$ & $-3,5-1,5$ & $-4,0-1,0$ & $-5,0-0,5$ & $-5,5-0,0$ & $-7,0--1,0$ & $-8,0--1,0$ \\
\hline $\begin{array}{l}\text { 8-Foot Up \& Go } \\
\text { (detik) }\end{array}$ & $6.0-4,4$ & $6,4-4,8$ & $7,1-4,9$ & $7,4-5,2$ & $8,7-5,7$ & $9,6-6,2$ & $11,5-7,3$ \\
\hline
\end{tabular}

\section{HASIL DAN PEMBAHASAN}

Analisis data yang digunakan menggunakan analisis statistik Uji Paried Sampel $t$ Test, menganalisis pengujian yang sebenarnya ingin diketahui apakah proposi yang kita peroleh dari suatu pengamatan sejumlah sampel tertentu (ukuran sampel sebanyak n) memiliki perbedaan yang Jurnal Penelitian Pendidikan signifikan atau tidak terhadap proposi populasinya pada tingkat signifikansi tertentu.

Berdasarkan dari hasil pengolahan dan analisis data terdapat beberapa hal yang perlu dibahas. Dalam penelitian ini dibahas mengenai pengaruh latihan kapha yoga terhadap penurunan tekanan darah dan 
kebugaran lansia, diperoleh bahwa terdapat pengaruh latihan kapha yoga terhadap penurunan tekan darah dan peningkatann kebugaran lansia. Berdasarkan analisis data menyatakan bahwa kriteria penerimaan dan penolakan hipotesis adalah terima $\mathrm{H} 0$, jika $-\mathrm{t}(1-1 / 2 \alpha)<\mathrm{t}<\mathrm{t}(1-1 / 2 \alpha)$ dalam hal Ho ditolak. Untuk $\alpha=0,05$ dan $\mathrm{dk}(\mathrm{n}-1)=15$, Maka dari itu t-hitung $>$ t-tabel. dengan demikian hipotesis H1 diterima bahwa terdapat pengaruh latihan kapha yoga terhadap penurunan tekanan darah dan penigkatan kebugaran lansia.

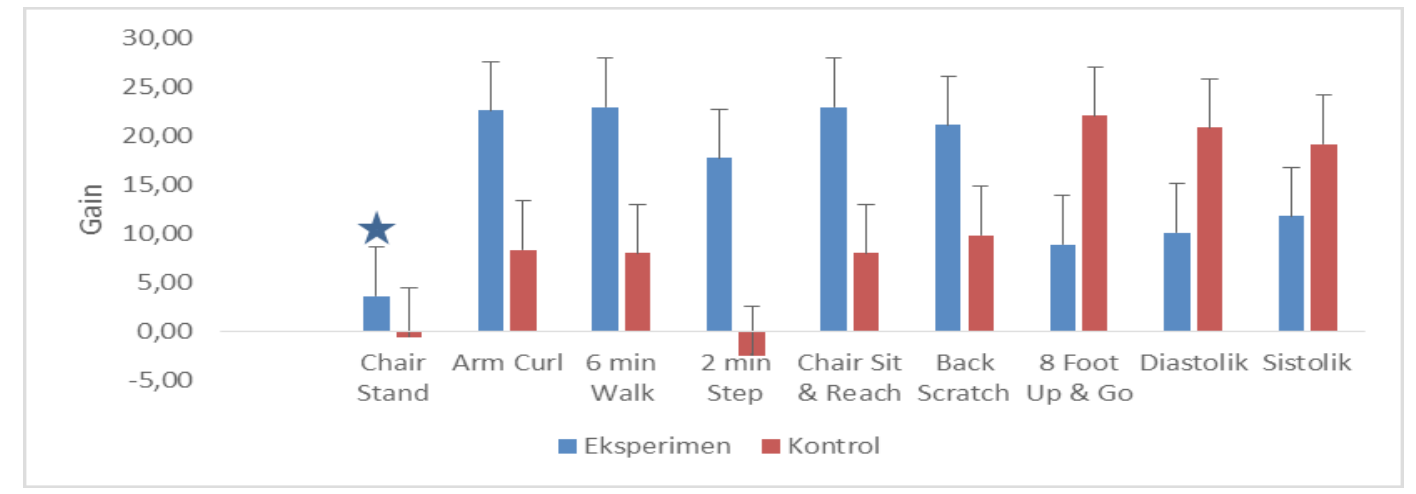

Grafik 1. Peningkatan Kebugaran Jasmani dan Penurunan Tekanan Darah Lansia Setelah Treatment Kapha Yoga

Dari Grafik 1 dapat dilihat bahwa hasil dari penelitian pada peningkatan kebugaran jasmani dan penurunan tekanan darah lansia pada kelompok eksperimen terdapat perbedaan yang signifikan dari pretest dan posttest. Sedangkan pada kelompok kontrol tidak terlihat perbedaan yang signifikan dari pretest dan posttest.

Dalam penelitian ini olahraga yang diberikan adalah latihan senam yoga, yoga merupakan suatu olahraga yang memadukan antara latihan fisik, pernapasan, konsentrasi dan relaksasi, yoga merupakan olahraga yang murah meriah dan tidak sulit, yoga dapat dilakukan sendiri maupun bersamasama dan dapat dilakukan kapanpun dan dimanapun bahkan oleh siapapun. Dan belum adanya penelitian mengenai pengaruh latihan yoga terhadap penurunan tekanan darah dan meningkatkan kebugaran pada lansia. Dengan demikian, untuk mengisi kekosongan penelitian dan untuk menguatkan teori yang ada, peneliti menerapkan latihan senam yoga yang diharapkan dapat menguatkan bukti empirik bahwa latihan yoga dapat menurunkan atau mengurangi tekanan darah dan meningkatkan kebugaran khususnya pada lansia.

\section{KESIMPULAN}

Terdapat pengaruh yang signifikan dari latihan Kapha Yoga terhadap penurunan tekanan darah pada lansia. Artinya, bahwa penerapan latihan metode dengan Kapha Yoga sangat bermanfaat, karena yoga dirancang untuk membawa keseimbangan bagi individu dengan memperhatikan empat aspek sekaligus, yaitu kesehatan fisik, mental, emosional, dan spiritual (Ross, Friedmann, Bevans, \& Thomas, 2012). Maka dari itu kapha yoga baik untuk siapa saja khususnya pada lansia.

Terdapat pengaruh yang signifikan dari latihan Kapha Yoga terhadap peningkatan kebugaran lansia. Artinya, bahwa penerapan latihan metode dengan Kapha Yoga sangat bermanfaat bagi kesehatan fisik dan juga meningkatkan kebugaran jasmani khususnya pada lansia. Karena lansia tingkat kebugaraanya menurun dan perlu ditangani dengan latihan olahraga yang tidak bersifat explosive maximal dan emotional sehingga tidak boleh ada unsur kompetisi didalamnya. 


\section{DAFTAR RUJUKAN}

Andari, Y. (2017, August 31). Pengaruh Latihan Kapha Yoga Terhadap Konsentrasidan Kualitas Hidup. Universitas Pendidikan Indonesia.

Anderson, B. E., \& Bliven, K. C. H. (2017). The Use of Breathing Exercises in the Treatment of Chronic, Nonspecific Low Back Pain. Journal of Sport Rehabilitation, 26(5), 452-458. https://doi.org/10.1123/ jsr.2015-0199

Anggraeni, R. (2017). MNC Channels Sadarkan Masyarakat Pentingnya Yoga untuk Kesehatan.

Blair, S. N., Kohl, H. W., Paffenbarger, R. S., Clark, D. G., Cooper, K. H., \& Gibbons, L. W. (1989). Physical Fitness and All-Cause Mortality: A Prospective Study of Healthy Men and Women. JAMA, 262(17), 2395-2401. https://doi.org/10.1001/JAMA.1989.03430170057028

Dinata, W. W. (2015). Menurunkan Tekanan Darah Pada Lansiamelalui Senam Yoga. JORPRES (Jurnal Olahraga Prestasi), 11(2), 77-90.

Eda, N., Ito, H., Shimizu, K., Suzuki, S., Lee, E., \& Akama, T. (2018). Yoga stretching for improving salivary immune function and mental stress in middle-aged and older adults. Journal of Women \& Aging, 30(3), 227-241. https://doi.org/10.1080/08952841.2017.1295689

Fraenkel, J. R., Wallen, N. E., \& Hyun, H. H. (2012). How to design and evaluate research in education (8 edition). New York: McGraw-Hill Humanities/Social Sciences/Languages.

Gain, R. (2011). Pengobatan Alternatif untuk Mengatasi Tekanan Darah. Jakarta: Gramedia Pustaka Utama.

Giriwijoyo, S. H. Y. S. (2016). Kesehatan, Olahraga dan Kinerja. Bandung: CV Bintang Warliantika.

Jones, C. J., \& Rikli, R. E. (2002). Measuring functional fitness of older adults. The Journal on Active Aging, 1(3), 24-30.

Kusmaedi, N. (2008). Olahraga Lansia. Bandung: CV. Bintang Warli Artika.

Lebang, E. (2010). Yoga Sehari-hari Untuk Kesehatan. Jakarta: Pustaka Bunda.

Naik, A., Patel, S., DA, B., \& Verma, M. (2016). Effect of Rajyoga Meditation on Intelligence Quotient of Attention Deficit Hyperactivity Disorder. Journal of Yoga \& Physical Therapy, 06(02), 1-2. https://doi. org/10.4172/2157-7595.1000242

Pescatello, L. S., Franklin, B. A., Fagard, R., Farquhar, W. B., Kelley, G. A., Ray, C. A., \& American College of Sports Medicine. (2004). American College of Sports Medicine position stand. Exercise and hypertension. Medicine and Science in Sports and Exercise, 36(3), 533-553.

Program, N. H. B. P. E. (2004). The Seventh Report of the Joint National Committee on Prevention, Detection, Evaluation, and Treatment of High Blood Pressure. The Seventh Report of the Joint National Committee on Prevention, Detection, Evaluation, and Treatment of High Blood Pressure. National Heart, Lung, and Blood Institute (US).

Raghuraj, P., \& Telles, S. (2004). Right uninostril yoga breathing influences ipsilateral components of middle latency auditory evoked potentials. Neurol Sci, 25(1), 274-280. https://doi.org/10.1007/s10072-0040354-9

Rahajeng, E., \& Tuminah, S. (2009). Prevalensi Hipertensi dan Determinannya di Indonesia. Maj Kedokt Indon, 59(12), 580-587.

Ross, A., Friedmann, E., Bevans, M., \& Thomas, S. (2012). Frequency of Yoga Practice Predicts Health: Results of a National Survey of Yoga Practitioners. Evidence-Based Complementary and Alternative Medicine, 2012, 1-10. https://doi.org/10.1155/2012/983258

Ross, A., \& Thomas, S. (2010). The Health Benefits of Yoga and Exercise: A Review of Comparison Studies. The Journal of Alternative and Complementary Medicine, 16(1), 3-12. https://doi.org/10.1089/ acm.2009.0044

Sindhu, P. (2009). Hidup Sehat Dan Seimbang Dengan Yoga: Daily Practice. Bandung: Qanita.

Sugiyono. (2016). Metode Penelitian Kuantitatif Kualitatif dan R\&amp;D. Bandung: Alfabeta.

Suherman, A. (2002). Penelitian Korelasional Dan Komparasi Dalam Kurikulum Dan Pengajaran. Makalah. Bandung. Pascasarjana UPI.

Taringan. (2016). Effect Of Scientific Approach In Physical Education Learning Toward Concentration And Spatial Inteligence of Primary School Students In Mountainous Area. In The International Conference on Sport Science, Health, and Physical Education (ICSSHPE 2016) - "Strategies Towards The 21st Century Challenges on Sport Sciences” (pp. 40-59). Bandung: ICSSHPE Conference. 